\title{
ANTI-CATARACT ACTIVITY OF GARCINIA INDICA AGAINST NAPHTHALENE-INDUCED CATARACT IN RATS
}

\author{
MILAP R PATEL, PATEL BG \\ Department of Pharmacology and Toxicology, Charotar University of Science and Technology, Changa, Gujarat, India. \\ Email: milaprpatel@yahoo.com
}

Received: 29 January 2017, Revised and Accepted: 28 February 2018

\begin{abstract}
Objective: The objective of this study is to investigate the anti-cataract activity of the aqueous extract of Garcinia indica (AGI) fruit rinds on naphthalene-induced cataract using rats.

Methods: Anti-cataract activity of AGI was evaluated using naphthalene model. Rats were divided into five groups ( $\mathrm{n}=6$ in each). Naphthalene solution was prepared by dissolving naphthalene in warm corn oil and administered at the dose of $0.5 \mathrm{~g} / \mathrm{kg} / \mathrm{day}$ p.o. for first 3 days and $1 \mathrm{~g} / \mathrm{kg} / \mathrm{day}$ p.o. thereafter for the induction of cataract. Group I normal control received corn oil $5 \mathrm{ml} / \mathrm{kg} /$ day. Group II cataract control received naphthalene solution. Group III received Vitamin E 50 mg/kg/day p.o., and Groups IV and V received AGI 200 mg/kg/day p.o and 400 mg/kg/day p.o., respectively, along with the naphthalene solution for 28 days. At the end of the treatment, levels of malondialdehyde, lipid hydroperoxides (LH), carbonyl and sulfhydryl content, and enzymatic and non-enzymatic antioxidants in lens homogenate were measured.
\end{abstract}

Results: Administration of naphthalene produced a mature cataract and an increase in the opacity index. A significant increase in LH and protein carbonyl content while decrease in protein SH content and antioxidant enzymes was found in naphthalene control group as compared to normal control group. Simultaneous administration of AGI and naphthalene delayed the onset and maturation of cataract.

Conclusion: The present investigation suggests that AGI protected the lens against naphthalene-induced oxidative damage which might be responsible for delaying the progression of cataract.

Keywords: Garcinia indica, Cataract, Naphthalene, Antioxidant, Oxidative stress.

(C) 2018 The Authors. Published by Innovare Academic Sciences Pvt Ltd. This is an open access article under the CC BY license (http://creativecommons. org/licenses/by/4. 0/) DOI: http://dx.doi.org/10.22159/ajpcr.2018.v11i6.24913

\section{INTRODUCTION}

Cataract may be defined as a visual impairment causing disturbance in the lens transparency which occurs mainly due to opacification or cloudiness of crystalline lens or optical dysfunction. Cataract reduces the amount of incoming light and results in deterioration of vision [1]. Cataract is the most frequent cause of avoidable blindness and visual impairment worldwide and more so in developing countries, especially for the elderly because the incidence of cataracts increases with increasing age $[2,3]$. From the public health perspective, it is important to identify the risk factors affecting the development and progression of cataract $[4,5]$.

At present, very few medications are available to cure or prevent cataracts. The symptoms of early cataract may be improved with new eye glasses, brighter lightening, anti-glare sun glasses, or magnifying lens. If these measures do not help, surgery is the only effective treatment $[2,6,7]$. Surgery is recognized as one of the safest procedures, forbye there are significant rate of complications which may lead to irreversibly blind eyes [3]. Furthermore, an artificial lens just does not have the overall optical qualities of a normal lens [8]. Thus, much eagerness is being laid on identification of natural compounds that will help to prevent cataractogenesis [3].

Large numbers of medicinal plants and synthetic compounds have been reported to possess anti-cataractogenic properties [6]. Various herbal drugs such as Ocimum sanctum, Emblica officinalis, Ginkgo biloba, and Momordica charantia were shown to delay the onset and progression of cataract development in experimental animals [9].

Garcinia indica commonly called as Kokum belongs to the family Clusiaceae (or Guttiferae according to the old classification) [9].
Medicinally useful part of Kokum is its fruit rinds which have multitude of health benefits. Its major phytoconstituents are garcinol, isogarcinol and camboginol, anthocyanins, hydroxycitric acid (HCA), HCA lactone, polyphenols, citric acid, and oxalic acid. The plant is pharmacologically studied for its anti-oxidative, anti-glycation, free radical scavenging, anti-ulcer, antibacterial, hepatoprotective, antidiabetic, anti-hypercholesterolemic, anticancer, anti-inflammatory, and antidepressant activities $[10,11]$. However, anti-cataract activity of G. indica is not reported to the date.

In the light of above information, the present study aimed to evaluate the anti-cataract activity of the aqueous extract of $G$. indica (AGI) using naphthalene-induced cataract model in rats.

\section{METHODS}

Drugs and chemicals

Naphthalene and Vitamin E were procured from SD fine chemicals, Mumbai, India. Remaining all other drugs and chemicals used in the study were obtained commercially and of analytical grade.

\section{Collection and authentication of plant material}

The fruit rinds of $G$. indica were procured from local market of the Anand city, Gujarat, India. The plant material was authenticated by Dr. A. M. Patel, Botanist (taxonomist), J. and J. Science College, Nadiad, Gujarat, India; a voucher specimen of the plant was deposited in the institutional herbarium with voucher No. 2016/MP/GI.

\section{Preparation of the extract}

The fruit rinds were shade dried and subjected to size reduction using mixer grinder to obtain a coarse powder. About $200 \mathrm{~g}$ powder 
was defatted with petroleum ether $\left(40-60^{\circ} \mathrm{C}\right)$ and macerated with chloroform water IP in a conical flask closed with cotton plug for 7 days with occasional shaking at room temperature. Then, it was filtered and concentrated using a rotary evaporator to yield aqueous extract. The extract was labeled properly and stored in a desiccator for use in subsequent experiments [12].

\section{Preliminary phytochemical analysis}

The AGI was subjected to preliminary phytochemical screening to reveal the presence of various phytoconstituents according to the methods outlined in Khandelwal 2008 [13].

\section{Animals}

Wistar rats (120-180 g) of either sex were procured from the Zydus Research Centre, Ahmedabad (Gujarat, India). On arrival, all animals were maintained in an approved housing facility of the institute and provided a standard laboratory diet (certified Amrut brand rodent feed, Pranav Agro Industries, Pune, India) and water ad libitum; animals were maintained at ambient temperature $\left(22 \pm 2^{\circ} \mathrm{C}\right)$, at a relative humidity $\left(55 \pm 2^{\circ} \mathrm{C}\right)$, and with a $12 \mathrm{~h}$ light-dark cycle. The Institutional Animal Ethics Committee approved the experimental protocol (Approval No.RPCP/IAEC/2016-2017/R1). During exposure regimens, animals were only given freshly prepared solutions of drugs or chemicals.

\section{Acute oral toxicity}

Acute oral toxicity study was carried out using Wistar rats by "fixed dose" method of OECD guideline number 420 adopting a starting dose of $2000 \mathrm{mg} / \mathrm{kg}$ body weight. The animals were observed for toxic effects or mortality up to 14 days with AGI [11].

\section{Experimental protocol}

Preparation of naphthalene solution

Naphthalene $(10 \%)$ was dissolved in warm corn oil at $60^{\circ} \mathrm{C}$ for $30 \mathrm{~min}$ [14].

\section{Induction of cataract}

Wistar rats of either sex weighing 120-180 g were randomly divided into five groups each comprising of 6 rats. Group I served as normal control received corn oil $5 \mathrm{ml} / \mathrm{kg} /$ day, Group II served as cataract control received naphthalene $0.5 \mathrm{~g} / \mathrm{kg} /$ day p.o. for first 3 days and $1 \mathrm{~g} / \mathrm{kg} /$ day p.o. thereafter, Group III received Vitamin E $50 \mathrm{mg} / \mathrm{kg} /$ day p.o., and Groups IV and V received AGI $200 \mathrm{mg} / \mathrm{kg} /$ day p.o and $400 \mathrm{mg} / \mathrm{kg} /$ day p.o., respectively, along with the naphthalene solution. All the groups were treated for 28 days $[14,15]$.

\section{Examination of the eyes}

Eyes of the rats were examined daily using an ophthalmoscope for the morphological changes in the lens. Examination was performed after dilating the pupil with $1 \%$ tropicamide solution. The lenses were examined twice a week during the first 2 weeks and thereafter at weekly intervals [16-18].

\section{Preparation of the lens}

After 28 days, the rats were anesthetized and lenses were dissected out, immediately rinsed with ice-cold saline. Each pair of lens was homogenized in $2 \mathrm{ml}$ of ice-cold phosphate buffer ( $20 \mathrm{mM}, \mathrm{pH}$ 7.4), centrifuged, and the supernatant was used for the analysis of carbonyl and sulfhydryl content [19], lipid peroxidation, malondialdehyde (MDA), lipid hydroperoxides (LH) [20], and total protein [21]. Enzymatic antioxidant such as superoxide dismutase (SOD) was determined by the inhibition of auto catalyzed adrenochrome formation in the presence of the homogenate at $480 \mathrm{~nm}$ [22]. Catalase (CAT) activity was estimated by the catalysis of $\mathrm{H}_{2} \mathrm{O}_{2}$ to $\mathrm{H}_{2} \mathrm{O}$ in an incubation mixture (adjusted to $\mathrm{pH} 7.0$ ) and recorded at $254 \mathrm{~nm}$ [23]. Glutathione reductase (GR) activity was determined spectrophotometrically by the decrease in absorbance of NADPH at $340 \mathrm{~nm}$ [24]. Glutathione peroxidase ( $\mathrm{GP}_{\mathrm{X}}$ ) activity was measured by the procedure of Paglia and Valentine, 1967 [25]. The estimation of non-enzymatic antioxidant-reduced glutathione (GSH) was based on the reaction of reduced GSH with dithionitrobenzoic acid (DTNB) to give a compound that absorbs at $412 \mathrm{~nm}$ [26].

\section{Statistical analysis}

Results are reported as the mean \pm standard error of the mean (SEM). All statistical analyses were performed using Graph Pad software (Version 7) using one-way analysis of variance followed by Dunnett's t-test to make statistical comparison between the various treatment groups. The results were considered statistically significant at $\mathrm{p}<0.05$, $\mathrm{p}<0.01$, and $\mathrm{p}<0.001$.

\section{RESULTS}

The preliminary qualitative phytochemical screening of the AGI revealed the presence of alkaloids, flavonoids, tannins and phenolic compounds, carbohydrates, glycosides, and carotenoids.

The acute toxicity study of AGI revealed no gross evidence of abnormalities or mortality at a maximum tolerated dose level of $2000 \mathrm{mg} / \mathrm{kg}$ p.o.

Naphthalene administration for 28 days produced a significant $(p<0.01)$ increase in the free carbonyl groups of lens proteins evident in cataract control group when compared to normal control. An increase in dinitrophenylhydrazine reactive carbonyls was accompanied by a significant $(\mathrm{p}<0.01)$ decrease in SH content. Treatment with the AGI (200 and $400 \mathrm{mg} / \mathrm{kg}$ ) and Vitamin E (50 mg/kg) significantly $(\mathrm{p}<0.01)$ decreased the carbonyl content and increased the SH content when compared to cataract control group (Table 1).

A significant $(p<0.01)$ decrease in the level of total protein and increase in the level of MDA and LH were observed in cataract control group when compared to normal control. Treatment with the AGI (200 and $400 \mathrm{mg} / \mathrm{kg}$ ) and Vitamin E (50 mg/kg) simultaneously with naphthalene for 28 days caused a significant $(\mathrm{p}<0.01)$ decrease in the MDA and LH and an increase in total protein content (Table 2).

Furthermore, naphthalene administration produced a significant $(p<0.01)$ decrease in the enzymatic antioxidants such as SOD, CAT, GR, and GPx and the non-enzymatic antioxidant GSH in cataract control group compared to normal control. Treatment with the AGI (200 and $400 \mathrm{mg} / \mathrm{kg})$ and Vitamin E $(50 \mathrm{mg} / \mathrm{kg})$ significantly $(\mathrm{p}<0.01)$ restored the levels of both enzymatic and non-enzymatic antioxidants almost similar to the normal control group. Overall, there was a dosedependent increase in the activity of the AGI. The activity produced by the standard Vitamin $\mathrm{E}$ was found to be the highest among the groups tested (Table 3).

\section{DISCUSSION}

Cataract is one of the leading causes of visual disability culminating to blindness. It is an age-related phenomenon where oxidative stress plays an important role. Although surgery is the only effective treatment nowadays, certain limitations have stimulated experimental cataract research on laboratory animals to determine the incidence, prevalence, and risk factors for the development of cataract to focus on the preventive aspects of cataract $[2,15]$.

Table 1: Effect of AGI on lens carbonyl and sulfhydryl content

\begin{tabular}{lll}
\hline Groups & $\begin{array}{l}\text { Carbonyl content } \\
\text { (nmoles/mg } \\
\text { protein) }\end{array}$ & $\begin{array}{l}\text { Sulfhydryl content } \\
\text { (nmoles/mg } \\
\text { protein) }\end{array}$ \\
\hline Normal control & $3.39 \pm 0.11$ & $34.01 \pm 0.48$ \\
Cataract control & $8.04 \pm 0.15^{\# \#}$ & $21.92 \pm 0.63^{\# \#}$ \\
Vitamin E (50 mg/kg) & $4.85 \pm 0.13^{* *}$ & $32.49 \pm 0.85^{* *}$ \\
AGI $(200 \mathrm{mg} / \mathrm{kg})$ & $5.71 \pm 0.10^{* *}$ & $28.49 \pm 1.02^{* *}$ \\
AGI $(400 \mathrm{mg} / \mathrm{kg})$ & $5.16 \pm 0.11^{* *}$ & $30.86 \pm 0.85^{* *}$ \\
\hline
\end{tabular}

Data represent mean \pm SEM, $n=6$ in each group. ${ }^{\# \#} \mathrm{p}<0.01$ when compared to normal control, ${ }^{* *} \mathrm{p}<0.01$ when compared to cataract control (one-way ANOVA followed by Dunnett's test). AGI: Aqueous extract of Garcinia indica, ANOVA: Analysis of variance, SEM: Standard error of the mean 
Table 2: Effect of AGI on lens total protein, MDA, and LH

\begin{tabular}{llll}
\hline Groups & Protein (nmoles/min/mg wet tissue) & MDA (nmoles/min/mg protein) & LH (nmoles/min/mg protein) \\
\hline Normal control & $1743 \pm 4.27$ & $44.35 \pm 1.20$ & $0.56 \pm 0.02$ \\
Cataract control & $670.3 \pm 1.37^{\# \#}$ & $98.98 \pm 0.26^{\# \#}$ & $2.62 \pm 0.01^{\# \#}$ \\
Vitamin E $(50 \mathrm{mg} / \mathrm{kg})$ & $1479 \pm 1.87^{* *}$ & $46.68 \pm 3.14^{* *}$ & $0.70 \pm 0.02^{* *}$ \\
AGI $(200 \mathrm{mg} / \mathrm{kg})$ & $1126 \pm 2.16^{* *}$ & $85.67 \pm 0.80^{* *}$ & $0.89 \pm 0.02^{* *}$ \\
AGI $(400 \mathrm{mg} / \mathrm{kg})$ & $1296 \pm 0.71^{* *}$ & $55.78 \pm 0.63^{* *}$ & $0.78 \pm 0.01^{* *}$ \\
\hline
\end{tabular}

Data represent mean \pm SEM, $\mathrm{n}=6$ in each group. ${ }^{\# \#} \mathrm{p}<0.01$ when compared to normal control, ${ }^{* *} \mathrm{p}<0.01$ when compared to cataract control (one-way ANOVA followed by Dunnett's test). AGI: Aqueous extract of Garcinia indica, ANOVA: Analysis of variance, MDA: Malondialdehyde, LH: Lipid hydroperoxides, SEM: Standard error of the mean

Table 3: Effect of AGI on lens enzymatic and non-enzymatic antioxidants

\begin{tabular}{lllll}
\hline Groups & $\begin{array}{l}\text { CAT } \\
\text { (nmoles/min/mg } \\
\text { protein) }\end{array}$ & $\begin{array}{l}\text { SOD } \\
\text { (nmoles/min/mg } \\
\text { protein) }\end{array}$ & $\begin{array}{l}\text { GR } \\
\text { (nmoles/min/mg } \\
\text { protein) }\end{array}$ & $\begin{array}{l}\text { GPx } \\
\text { (nmoles/min/mg } \\
\text { protein) }\end{array}$ \\
\hline Normal Control & $8.70 \pm 0.15$ & $44.35 \pm 1.20$ & $32.50 \pm 0.09661$ & $48.73 \pm 0.1308$ \\
Cataract Control & $4.48 \pm 0.09^{\# \#}$ & $98.98 \pm 0.26^{\# \#}$ & $19.72 \pm 0.14^{\# \#}$ & $24.5 \pm 0.1^{\# \#}$ \\
Vitamin E (50 mg/kg) & $8.18 \pm 0.20^{* *}$ & $46.68 \pm 3.14^{* *}$ & $31.18 \pm 0.24^{* *}$ & $46.85 \pm 0.43^{* *}$ \\
AGI (200 mg/kg) & $5.33 \pm 0.06^{* *}$ & $85.67 \pm 0.80^{* *}$ & $23.7 \pm 0.19^{* *}$ & $4.65 \pm 0.136^{\# \#}$ \\
AGI (400 mg/kg) & $5.95 \pm 0.20^{* *}$ & $55.78 \pm 0.63^{* *}$ & $27.98 \pm 0.27^{* *}$ & $28.50 \pm 0.08^{* *}$ \\
\hline
\end{tabular}

Data represent mean \pm SEM, $\mathrm{n}=6$ in each group. ${ }^{\# \#} \mathrm{p}<0.01$ when compared to normal control, ${ }^{* *} \mathrm{p}<0.01$ when compared to cataract control (one-way ANOVA followed by Dunnett's test). ANOVA: Analysis of variance. SEM: Standard error of the mean, CAT: Catalase, SOD: Superoxide dismutase, GR: Glutathione reductase, GPx: Glutathione peroxidase, GSH: Glutathione, AGI: Aqueous extract of Garcinia indica

It has been reported that administration of naphthalene causes cataract in both humans as well as rats $[27,28]$. Naphthalene-induced cataract has been used as an invaluable animal model to study the etiology of senile cataract in humans and to test potential anti-cataract drugs considering that the morphology and the toxic manifestations of naphthalene-induced cataract are reported to be similar as the age-related cataract [28]. Ingested naphthalene undergoes oxidative metabolism by cytochrome P450 enzymes in the liver to form naphthalene-1, 2-dihydrodiol (ND). Further, ND is metabolized to naphthoquinone (NQ) by an enzyme dihydrodiol dehydrogenase. The formation of $\mathrm{NQ}$ in the lens is theorized to be responsible for the formation of cataracts in naphthalene-fed rats [14,27,28]. NQ is believed to have higher cataractogenic potential than solely naphthalene [28].

$\mathrm{NQ}$ is highly reactive and induces the formation of reactive oxygen species (ROS). The resulting oxidative stress causes cataract. NQ briskly forms covalent bonds with various cellular thiols such as GSH, cysteine, and protein thiols. Furthermore, various oxidative insults help NQ to induce lens protein modification [14].

Free carbonyls and SH are suggestive of oxidative modifications of lens proteins. Decomposition of lipid peroxide in the lens initiates the chain reactions that cause increase in the protein carbonyl content and decrease in the protein SH content. SH oxidation through disulfide cross-linking and molecular aggregation leads to protein precipitation and lens opacification $[2,15]$. At the end of the study, biochemical analyses of eye lens proteins showed a significant elevation of carbonyl groups and depletion of SH groups in naphthalene-induced cataractous lenses when compared to normal control lenses. Treatment with the AGI dose dependently and significantly decreased the carbonyl content while increased the SH content compared to naphthalene control lenses. Vitamin E used as standard expectedly decreased the carbonyl content while increased the SH content, better than the AGI.

The products of lipid peroxidation are also assumed to cause cataract [28]. Lipid peroxidation is an autocatalytic and destructive process induced by free radicals which cause changes in biochemical processes and structural integrity leading to cellular damage [14]. MDA and LH are the secondary products of lipid peroxidation which are indicative of tissue damage. MDA and LH induce fragmentation of soluble lens proteins, modification of lens crystallins, and damage vital membrane structures, all accountable for increase in lens opacity [15]. In the present study, naphthalene-treated animals showed an increase in MDA and LH levels in lens. Treatment with the AGI simultaneously with naphthalene for 28 days caused a significant decrease in the lens MDA and LH while increased total protein level. This effect was almost similar to the Vitamin E-treated group.

The biological system possesses both the enzymatic and non-enzymatic antioxidants whose balance with free-radical production determines the status of oxidative stress of a cell $[29,30]$. Cataractous lenses have reportedly decreased antioxidant enzymes activity [30]. Thus, it necessitates importance to determine the levels of antioxidant enzymes such as SOD, CAT, GPx, and GSSH. The first enzyme involved in the antioxidant defense is SOD. It scavenges superoxide anion and converts it into hydrogen peroxide $\left(\mathrm{H}_{2} \mathrm{O}_{2}\right)[15,30]$.

CAT protects the cell from oxidative damage by $\mathrm{H}_{2} \mathrm{O}_{2}$ and hydroxyl radical. The enzyme GSSH catalyzes the conversion of oxidized glutathione (GSSG) to reduced GSH, thereby maintaining a constant level of GSH in a normal lens. GPx has a major role in degrading the levels of $\mathrm{H}_{2} \mathrm{O}_{2}$ in cells. Since GPx acts on hydroperoxides of unsaturated fatty acids, it plays an important role in protecting membrane lipids. Reduced GSH is an intracellular reductant which plays a major role in catalysis, metabolism, and transport. The normal lens contains a high concentration of GSH, which scavenges the toxic ROS [15]. Administration of naphthalene significantly decreased the activities of enzymatic and non-enzymatic antioxidants evidently in cataract control group as compared with the normal control group. However, the groups supplemented with the AGI produced a significant and dose-dependent increase in the level of antioxidant enzymes which is almost similar to the Vitamin E-treated group.

Hence, a conclusion can be drawn that $G$. indica exhibited potent anticataract activity against naphthalene-induced cataractogenesis in rats. This can be attributed to its antioxidant and free radical scavenging activities which might be helpful in preventing or slowing the progress of cataract formation.

\section{ACKNOWLEDGMENT}

The authors are thankful to Ramanbhai Patel College of Pharmacy, Charotar University of Science and Technology, for providing facility for research work. 


\section{AUTHOR'S CONTRIBUTIONS}

Authors listed on the title page have contributed substantially to the work.

\section{CONFLICT OF INTEREST}

The authors declare that there is no conflict of interest.

\section{REFERENCES}

1. Ushasree P, Madhuri M. Exploring medicinal plants for anti-cataract activity: A review. Ann Drug Disc Biomed Res 2014;1:30-8.

2. Aziz S, Konwar M, Das S. In-vitro anti-cataract activity of Hbiscusrosasinensis Linn on goat lens. Int J Pharm Pharm Sci 2015;7:334-6.

3. Umamaheswari M, Dhinesh S, Sivashanmugam T, Subhadradevi V, Puliyath J, Madeswaran A. Anticataract and antioxidant activities of Achyranthes aspera Linn. Against glucose-induced cataractogenesis using goat lenses. J Nat Prod Plant Resour 2012;2:153-61.

4. Patel P, Jivani N, Malaviya S, Gohil T, Bhalodia Y. Cataract: A major secondary diabetic complication. Int Curr Pharm J 2012;1:180-5.

5. Krishnaiah S, Vilas K, Shamanna BR, Rao GN, Thomas R, Balasubramanian D, et al. Smoking and its association with cataract: Results of the Andhra Pradesh eye disease study from India. Invest Ophthalmol Vis Sci 2005;46:58-65.

6. Patel DK, Prasad SK, Kumar R, Hemalatha S. Cataract: A major secondary complication of diabetes, its epidemiology and an overview on major medicinal plants screened for Anticataract activity. Asian Pac J Trop Dis 2011;1:323-9.

7. Kyselova Z. Different experimental approaches in modelling cataractogenesis: An overview of selenite-induced nuclear cataract in rats. Interdiscip Toxicol 2010;3:3-14.

8. Kyselova Z, Stefek M, Bauer V. Pharmacological prevention of diabetic cataract. J Diabetes Complications 2004;18:129-40.

9. Manish K, Arti G, Chhavi B, Javed A, Tyagi LK. Herbal treatment of cataract: A review. Int J Pharmacol Toxicol Sci 2012;2:15-24.

10. Ramachandran HD. Plant profile, phytochemistry and pharmacology of Garcinia indica: A review. Int J Pharm Sci Rev Res 2014;27:376-81.

11. Sathisha AD, Shivaprakash P, Balaji KS, Vigneshwaran V, Krupashree K, Jayarama S. Antide-pressant-like effect of the aqueous extract from Garcinia indica fruit in mice models of depression. Eur J Biomed Pharm Sci 2015;2:1133-40.

12. Khatib NA, Patil PA. Evaluation of Garcina indica whole fruit extracts for hypoglycemic potential in Streptozotocin induced hyperglycemic rats. Res J Pharm Tech 2011;4:999-1003.

13. Khandelwal KR, editor. Preliminary phytochemical screening. In: Practical Pharmacognosy Techniques and Experiments. $9^{\text {th }}$ ed. Pune,
India: Nirali Prakashan; 2008. p. 149-57.

14. Hammouda GA, Mohamed GF, Shaker SM, Mahmoud KH. The possible protective effect of curcumin on naphthalene induced cataract in rats (Histological and Scanning Electron Microscopic Study). Egypt J Histol 2009;32:315-23.

15. Umamaheswari M, Asokkumar K, Lalitha V, Sivashanmugam AT, Subhadradevi V. Anticataract and antioxidant activities of Citrus aurantium L. Peel extract against naphthalene induced cataractogenesis in rats. J Pharm Res 2011;4:680-2.

16. Sippel TO. Changes in the water, protein and glutathione contents of the lens in the course of galactose cataract development in rats. Invest Opthalmol 1966;5:568-75.

17. Umamaheswari M, Asokkumar K, Lalitha V, Sivashanmugam AT, Subhadradevi V, Neethu M. Anticataract activity of Erythrina stricta against naphthalene induced cataractogenesis in rats. Bangladesh $\mathrm{J}$ Pharmacol 2010;5:77-81.

18. Fukushi S, Merola LO, Kinoshita JH. Altering the course of cataracts in diabetic rats. Invest Ophthalmol Vis Sci 1980;19:313-5.

19. Lowry OH, Rosebrough NJ, Farr AL, Randall RJ. Protein measurement with the Folinphenol reagent. J Biol Chem 1951;193:265-75.

20. Altomare E, Grattagliano I, Vendemaile G, Micelli-Ferrari T, Signorile A, Cardia L. Oxidative protein damage in human diabetic eye: Evidence for retinal participation. Eur J Clin Invest 1997;27:141-7.

21. Niehaus WG Jr, Samuelsson B. Formation of malondialdehyde from phospholipid arachidonate during microsomal lipid peroxidation. Eur J Biochem 1968;6:126-310.

22. Kakkar P, Das B, Viswanathan PN. A modified spectrophotometric assay of superoxide dismutase. Indian J Biochem Biophys 1984;21:130-2.

23. Sinha AK. Colorimetric assay of catalase. Anal Biochem 1972;47:389-94.

24. Racker E. Glutathione reductase from bakers' yeast and beef liver. J Biol Chem 1955;217:855-65.

25. Paglia DE, Valentine WN. Studies on the quantitative and qualitative characterization of erythrocyte glutathione peroxidase. J Lab Clin Med 1967; 70:158-69

26. Ellman GL. Tissue sulfhydryl groups. Arch Biochem Biophys 1959;82:70-7.

27. Stohs SJ, Ohia S, Bagchi D. Naphthalene toxicity and antioxidant nutrients. Toxicology 2002;180:97-105.

28. Pandya U, Saini MK, Jin GF, Awasthi S, Godley BF, Awasthi YC, et al. Dietary curcumin prevents ocular toxicity of naphthalene in rats. Toxicol Lett 2000;115:195-204.

29. Thiagarajan R, Manikandan R. Antioxidants and cataract. Free Radic Res 2013;47:337-45

30. Sreeja S, Geyanthi GP, Devi SG. Status of enzymatic antioxidants in eye lens extracted from cataractous subjects. Int $\mathrm{J}$ Pharm Pharm Sci 2015;7:139-42. 